https://doi.org/10.47660/CBR.2020.16709

\title{
ANEMIA IN RHEUMATOID ARTHRITIS: CHARACTERISTIC AND PREVALENCE
}

\author{
Fernando Carvalho Nilsen ${ }^{1, *}$, Isadora Aparecida Gheralde ${ }^{1}$, Waldenise Cossermelli ${ }^{1}$ \\ 1. Faculdade de Medicina de Jundiaí, Jundiaí (SP), Brazil. \\ ${ }^{\star}$ Corresponding author: fernandocnilsen@gmail.com
}

\section{INTRODUCTION}

Rheumatoid arthritis (RA) is a disease that affects about $1 \%$ of the population, mainly women over 50 years of age. It is a systemic disease with articular and extra-articular symptoms that can trigger severe physical disabilities. It is a multifactorial disease with breach of immune tolerance and joint inflammation, where there are several types of triggers for activating the inflammatory response, with the release of inflammatory mediators such as interleukins (IL-1, TNF-alpha and IL-6). There is presence of autoreactive T cells, in addition to $\mathrm{B}$ cells with production of autoantibodies that will cause bone and cartilage destruction in synovial joints. One of the most prevalent complications in patients with RA is anemia, present in 30 to $70 \%$ of patients, which can be asymptomatic and be related to greater activity of the underlying disease.

\section{MATERIALS AND METHODS}

One hundred and twenty-four patients with rheumatoid arthritis were selected and evaluated for the presence, type of anemia and its relationship with the disease and other comorbidities that could influence the presence of anemia. The analysis was done through anamnesis, physical examination and laboratory tests. The data obtained will be analyzed statistically using the chi-square Pearson test and evaluated based on the null hypothesis.

\section{RESULTS}

The profile of patients with RA and anemia were white women, with no predominant age profile and both the presence of previous anemia and the increase in inflammatory tests (ESR and CRP), proved to be important risk factors in the development of anemia in RA and the most prevalent type was anemia of chronic disease, mainly in the beginning of the disease and secondly, iron deficiency anemia, with a greater importance in patients with more years of disease. Some secondary results were important, such as the use of immunobiologicals that were shown to be protective against the development of anemia in RA, compared to the use of synthetic MMCDs.

\section{CONCLUSION}

Therefore, the relationship hereby established between anemia and chronic RA led to a better understanding of this systemic manifestation that accompany the disease in its various stages as well as its treatment thus providing improvement in quality of life reducing symptoms such important symptoms as fatigue and prostration

\section{FUNDING}

Programas de Iniciação Científica e Tecnológica of Conselho Nacional de Desenvolvimento Científico e Tecnológico (CNPq-PIBIC). 